\title{
Trend and Factor Analysis of Office Related Research in LOIS Technical Committee
}

\author{
Toshihiko WAKAHARA $^{\dagger a)}$, Fellow, Toshitaka MAKI ${ }^{\dagger}$, Student Member, Noriyasu YAMAMOTO ${ }^{\dagger}$, Member, $^{2}$ \\ Akihisa KODATE ${ }^{\dagger \dagger}$, Manabu OKAMOTO ${ }^{\dagger \dagger \dagger}$, and Hiroyuki NISHI ${ }^{\dagger \dagger \dagger}$, Senior Members
}

SUMMARY The Life Intelligence and Office Information System (LOIS) Technical Committee of the Institute of Electronics, Information and Communication Engineers (IEICE) dates its origin to May 1986. This Technical Committee (TC) has covered the research fields of the office related systems for more than 30 years. Over this time, this TC, under its multiple name changes, has served as a forum for research and provided many opportunities for not only office users but also ordinary users of systems and services to present ideas and discussions. Therefore, these advanced technologies have been diffused from big enterprises to small companies and home users responsible for their management and operation. This paper sums up the technology trends and views of the office related systems and services covered in the 30 years of presentations of the LOIS Technical Committees by using the new literature analysis system based on the IEICE Knowledge Discovery system (I-Scover system).

key words: office study, LOIS, technical committee, technology trend, literature retrieval, I-Scover

\section{Introduction}

New technologies have been often introduced in advanced offices or big enterprises pursuing improved business efficiency. In order to solve office issues, an academic society named the Office Automation (OA) Society was founded in 1979 whose main goal was searching for efficient improvement of the office work. Later, the name of this Society was changed to Japan Society for Information and Management [1] in 2007. The main focus on the research of this society includes management, enterprise and social information systems in the office. Then the various technologies have been developed and experienced in the offices. Along with these activities, the Japan Society for Office Studies [2] was founded in 1999 to study the work style in the office and office environments, etc.

Since there was no study group related to the systems or network technologies of office matters, a new study group was established called Office System (OS) in the IEICE [3] in 1986. As the research viewpoint of each society is different, each study group has been progressed in each stand-

\footnotetext{
Manuscript received November 14, 2016.

Manuscript revised June 6, 2017.

Manuscript publicized July 21, 2017.

tThe authors are with Fukuoka Institute of Technology, Fukuoka-shi, 811-0295 Japan.

${ }^{\dagger}$ The author is with Tsuda University, Tokyo, 151-0051 Japan.

${ }^{+1}$ The author is with NTT Media Intelligence Laboratory, Yokosuka-shi, 239-0847 Japan.

${ }^{\dagger \dagger \dagger}$ The author is with Sojo University, Kumamoto-shi, 860-0082

a) E-mail: wakahara@ fit.ac.jp DOI: 10.1587/transinf.2016OFI0001
} Japan.
Table 1 TCs and Societies in IEICE.

\begin{tabular}{llllll}
\hline TSs & ESS & CS & ES & ISS & HCG \\
\hline General & 20 & 21 & 15 & 23 & 4 \\
\hline Ad-hoc & 0 & 8 & 7 & 4 & 5 \\
\hline
\end{tabular}

Table 2 Technical Committees in the ISS.

\begin{tabular}{lll}
\hline & Abbreviation & Formal Name \\
\hline 1 & MBE & ME and Bio Cybernetics \\
\hline 2 & LOIS & Life Intelligence and Office Information Systems \\
\hline 3 & IE & Image Engineering \\
\hline 4 & NLC & $\begin{array}{l}\text { Natural Language Understanding and Models of } \\
\text { Communication }\end{array}$ \\
\hline 5 & CPSY & Computer Systems \\
\hline 6 & COMP & Theoretical Foundations of Computing \\
\hline$\ldots$ & $\ldots$ & .. \\
\hline
\end{tabular}

point.

This paper presents the activities of the LOIS Technical Committee [4] of the Information and Systems Society (ISS) in the IEICE. This LOIS TC is derived from the above OS Technical Committee and has been developed. It is easy to get the office related research papers submitted in the IEICE by using the recently developed I-Scover system [5]. There are five societies in the ICICE as shown in Table 1. This Institute is composed of Engineering Sciences Society (ESS), Communications Society (CS), Electronics Society (ES), Information and Systems Society (ISS) and Human Communication Group (HCG). The LOIS TC is within the ISS. There are 23 Technical Committees in the ISS as shown in Table 2.

This paper is organized as follows. The outline and history of the LOIS TC is presented in Sect. 2. In Sect. 3, we present the new system for literature analysis which utilizes the I-Scover system along with the trends of the LOIS TC and conferences in recent 10 years. Then the factors of the trends, various time series analysis and keyword network graphs are also described in Sect. 3. In the final section, the conclusions for this paper are summarized.

\section{Outline of LOIS Technical Committee}

As stated in the previous section, the LOIS Technical Committee was initially founded as a special interest group known as the Office System (OS) Technical Committee. In

I-Scover is a registered trademark of the IEICE. 
Table 3 Keywords of LOIS Technical Committee.

\begin{tabular}{ll}
\hline Number & Keywords \\
\hline D141000 & Office Information Systems, e-Business Modelling \\
\hline D141001 & Office Architecture Models \\
\hline D141002 & SOHO and Telework Systems \\
\hline D141003 & Business Intelligence \\
\hline D141004 & Business Process Engineering \\
\hline D141005 & Business Support \\
\hline$\ldots$ & \multicolumn{1}{c}{$\ldots \ldots .}$. \\
\hline D141009 & Social Information Systems \\
\hline D141010 & Human Behavioral Science \\
\hline D141011 & Office Environment and Design \\
\hline$\ldots . .$. & $\quad \ldots . .$. \\
\hline D141018 & Construction of Enterprise Models and Business Process \\
\hline D141019 & Model Evaluation Techniques \\
\hline D141020 & Knowledge Sharing and Management Techniques \\
\hline D141021 & System Construction Techniques \\
\hline D141022 & Education, Human Resource Development, and \\
\hline & Authentication \\
\hline
\end{tabular}

this OS TC, the document related systems, multimedia communication systems in the offices or network application were mainly dealt with in the 1980 and 1990 era.

However, since the name of the OS TC was often confused with OS acronym standing for 'Operating System', the abbreviation was changed to the OFfice System (OFS) $\mathrm{TC}$ in 1999. In the following years, the topics of the presentation in the OFS TC have contained application of information systems and advanced systems using computer, so the name of the OFS TC was changed to Office Information System (OIS) in 2002. Furthermore, it was renamed as the Life Intelligence and Office Information Systems (LOIS) TC since the contents being discussed in the TC included the systems or services not only for business users but also for daily life activities for ordinary consumers. The keyword "Lifelog" is commonly used in the related presentations.

The main keywords for technical field classified in the LOIS TC are shown in Table 3 [6]. However, the keywords related to lifelogs are not included, so a revision of the table is necessary in the near future. On the other hand, the related fields are located in the number D140500 (Data engineering and Web information system), number D140600 (Information network), D140800 (Artificial Intelligence and Data mining) and D140900 (Human computer interaction) So the arrangement of the keyword table is also needed.

\section{Trend and Factor Analysis Based on the I-Scover System}

The activities of the Office related Technical Committee can be obtained by the new analysis system based on the IScover system in this section.

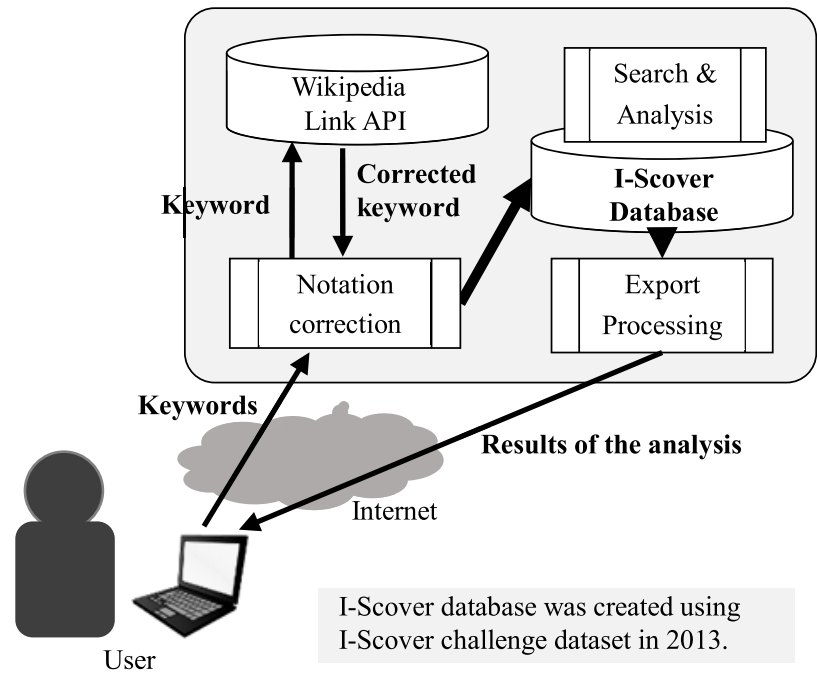

Fig. 1 System configuration of the new analysis system.

Table 4 I-Scover dataset.

\begin{tabular}{lcl}
\hline Items & Records & Contents \\
\hline Article & 234,364 & Article ID, Title, Abstract, Issued date, etc. \\
\hline Author & 775,910 & Article ID, Person ID, Organization ID. \\
\hline Person & 266,261 & Person ID, Person name, etc. \\
\hline Organization & 29,866 & Organization ID, Organization name, etc. \\
\hline Keyword & 946,808 & Article ID, Term ID. \\
\hline Term & 317,602 & Term ID, Term, External links, etc. \\
\hline
\end{tabular}

\subsection{The New Literature Analysis System}

We developed the new literature analysis system in order to identify the characteristic trend [7]. This system utilizes the Wikipedia Link API [8] together with I-Scover system to improve tracking over time given the fluctuation in notation commonly used. The first stage of I-Scover system was developed in April 2013. In this system, the papers are linked to another research papers by the metadata (Linked Open Data) in the external sites like CiNii [9].

The process flow of the new literature analysis system is shown in Fig. 1. Since the I-Scover system can only retrieve the literature from the metadata [10], the analysing function and visualizing functions are added through the IScover system. The Wikipedia Link API is introduced in order to reduce the impact of changing terminology.

If the keywords are entered into this system, the notation fluctuation is eliminated and the literature which is identified by the keywords are searched and presented.

The I-Scover dataset for this new literature analysis system is shown in Table 4. There are about 234,364 articles and 946,808 keywords in this archive. The specifications of the new analysis system are shown in Table 5 . In this system, MySQL is used as the database, Apache 2 
Table 5 Specifications of the new literature analysis system.

\begin{tabular}{ll}
\hline OS & CentOS 6.8, 64bit \\
\hline CPU & Intel (R) Core (TM) i7-4770K, 4 cores, 3.50GHz \\
\hline RAM & DDR3 16GB \\
\hline SSD & RAID 5, 406 GB \\
\hline Web server & Apache 2.2.15 \\
\hline Database & MySQL 5.1.73 \\
\hline $\begin{array}{l}\text { Development } \\
\text { language }\end{array}$ & PHP 5.3.3 \\
\hline Graph tool & JpGraph 3.0.7 \\
\hline
\end{tabular}
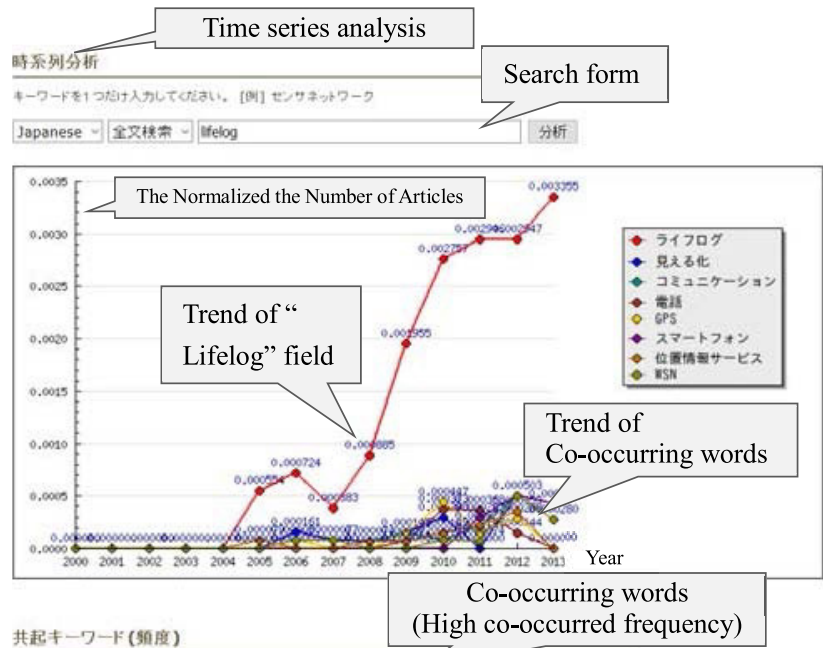

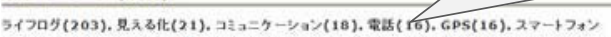

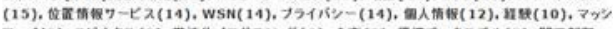

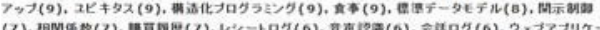

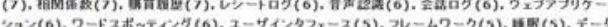

จ

Fig. 2 Time series analysis of "Lifelog".

is used as a Web server and the programming language is PHP5. JpGraph [11] is used as a graph library.

\subsection{Trend Analysis of LOIS Technical Committee}

By using this system, the time series trends of the technical papers of the LOIS Technical Committee, the Society Conference, General Conference and the FIT (Forum on Information Technology), papers from the International Conference, and IEICE Transactions on the Information and Systems Society were extracted and analyzed by the inputted keywords [12]. Figure 2 shows the results of time series analysis of the keyword "Lifelog" in the interval 2000 to 2013 in the LOIS TC literature. (The name of the TC had been changed from OIS to LOIS in 2009.) The results are normalized with the total volume of literature and has still greatly increased during that period. Then time series trends of other keywords co-occurring with "Lifelog" are also shown in this figure. These keywords include "GPS", "API", "Mashup", etc.

The time series analysis for the special keywords, "Lifelog" and "Web application", from 2000 to 2013 is shown in Fig. 3. This figure shows the co-occurring fre-

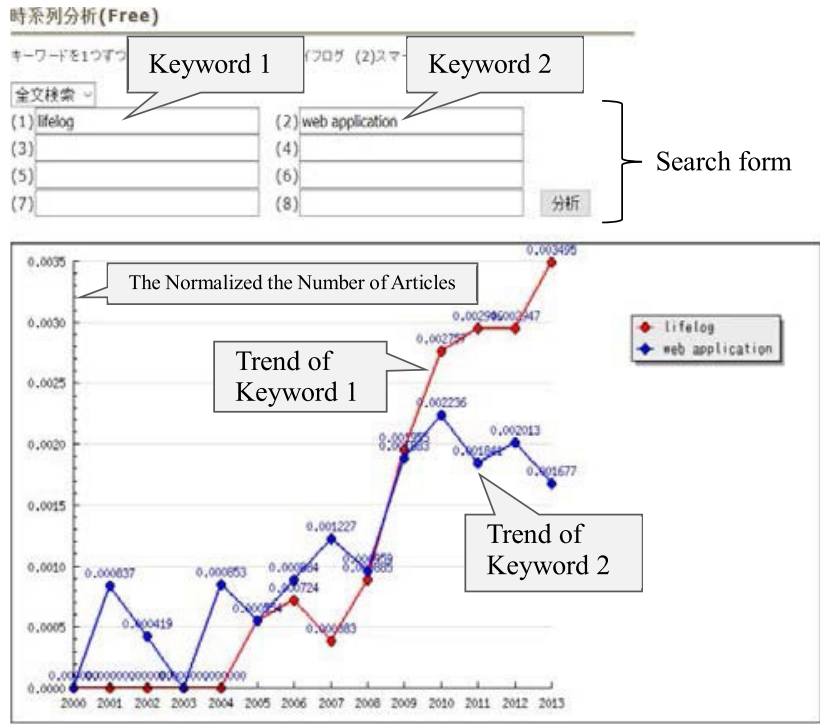

Fig. 3 Time series analysis of the special plural keywords.

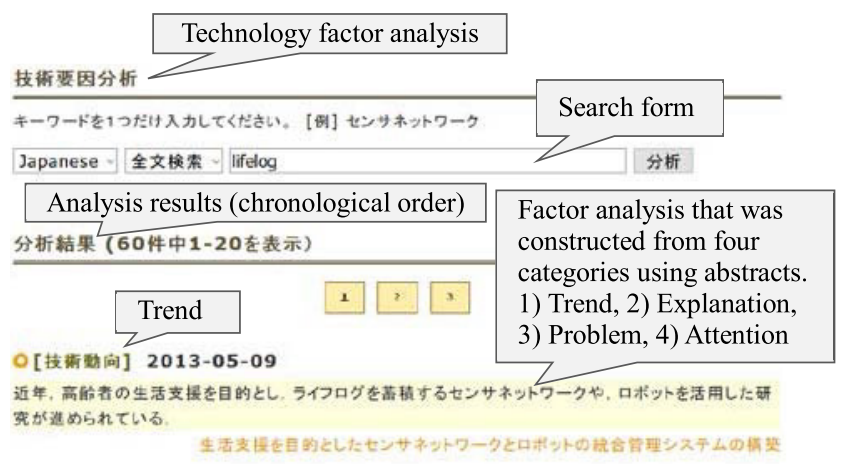

○[技斯䵥向] 2013-03-05

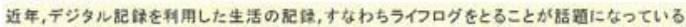

Explanation テスクフーว

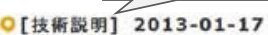

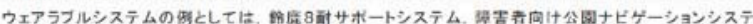

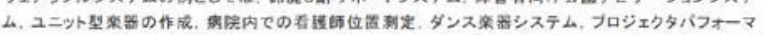

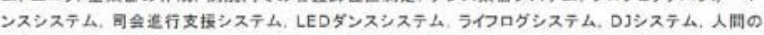

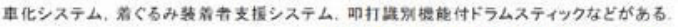

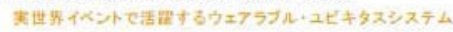

Fig. 4 Technology factor analysis.

quency characteristics of the two keywords. Although the frequency of the keyword "Lifelog" increases from about 2005 , the keyword "Web application" doesn't display a similar trend to the increase in "Lifelog". It is presumed that the various lifelog services are increasing year by year, but web application technology is in use from about 2000 and this well-established and saturated in 2010 era.

The technology factor analysis (技術要因分析) is shown in Fig. 4. This shows the examples of the analysis results from the abstracts of the papers.

The results are classified into 4 categories, namely, the technological Trend, Explanation, Problem and Attention. The trend of technological factor can be estimated or at least a hints of solutions may be obtained from the article abstract. 
Table 6 Keywords ranked top 10 in the LOIS TC paper.

\begin{tabular}{lllll}
\hline $\mathbf{2 0 0 9}$ & $\mathbf{2 0 1 0}$ & $\mathbf{2 0 1 1}$ & $\mathbf{2 0 1 2}$ & $\mathbf{2 0 1 3}$ \\
\hline Lifelog & Lifelog & Lifelog & Lifelog & Lifelog \\
\hline Home network & GPS & $\begin{array}{l}\text { Knapsack } \\
\text { encryption }\end{array}$ & Sensor network & Smart phone \\
\hline e-Learning & $\begin{array}{l}\text { Sensor } \\
\text { Network }\end{array}$ & $\begin{array}{l}\text { Location } \\
\text { information }\end{array}$ & Security & Management \\
\hline GPS & Mashup & GPS & Smart phone & $\begin{array}{l}\text { Image } \\
\text { processing }\end{array}$ \\
\hline Encryption & Security & QR code & Authentication & QR code \\
\hline Recommend & User support & $\begin{array}{l}\text { Mobile } \\
\text { terminal }\end{array}$ & $\begin{array}{l}\text { Location } \\
\text { information }\end{array}$ & GPS date \\
\hline Pulse rate & Scheduler & $\begin{array}{l}\text { Encryption } \\
\text { code }\end{array}$ & Cloud & Vocabulary \\
& learning \\
\hline Elliptic curve & Firefox & Security & $\begin{array}{l}\text { Electronic } \\
\text { watermark }\end{array}$ & Food log \\
\hline Pairing & Community & $\begin{array}{l}\text { Low density } \\
\text { attack }\end{array}$ & $\begin{array}{l}\text { No-contact } \\
\text { IC card }\end{array}$ & Communication \\
\hline QR code & Standard date & $\begin{array}{l}\text { Formal } \\
\text { verification }\end{array}$ & Word spotting & Home network \\
& model & & & \\
\hline
\end{tabular}

Then the keywords registered in the paper are very important. Table 6 shows the top 10 ranked keywords in the papers of the LOIS TC for past 5 years as obtained through the new literature analysis system. From this table, it is evident that the keyword "Lifelog" appears most frequently and can be considered the most important in LOIS TC. After the change of the name of the TC, "Lifelog" and related keywords, "GPS", "Location information", "Mashup", "Smart phone", "Mobile phone", "Food log" etc., are frequently utilized in the presented literature.

Then the recent time series analysis of the literature and number of authors per year are shown in Fig. 5.

From this figure, the numbers of articles and authors have been increasing after 2009 and it can be said that research activities have been invigorated since 2009 .

The LOIS TC is ordinarily held every two months and cooperated with other TCs or other such as Document Communication (DC) TC of the Information Processing of Japan (IPSJ).

Figure 6 shows the number of articles per two month interval. Before 2009, the number of articles was typically 10 or less. But the number of articles has increased, especially in March. This is because the venue had been moved from Tokyo to Okinawa and the conference became popular destination as a graduation trip for students.

Table 7 shows the topics and keywords which are discussed in the LOIS TC. This is shown in the Web page of LOIS TC. The topics are composed of 8 topics, namely, "Lifelog", "Office model", "Communication", "Data mining", "System architecture", "Network", "Security" and "Human interface". The top 10 ranking keywords in the period of between 2009 and 2013 are shown in Table 6. These keywords are obtained from the system and useful for researchers to select the presenting conference.

Figure 7 shows the number of articles in each field for approximately ten years. In this figure, because there are various systems and services in the "System architecture" field, these make up the largest in total articles. The second largest category is "Network". Thus the literatures covering "Lifelog" field is the third largest. We can assume

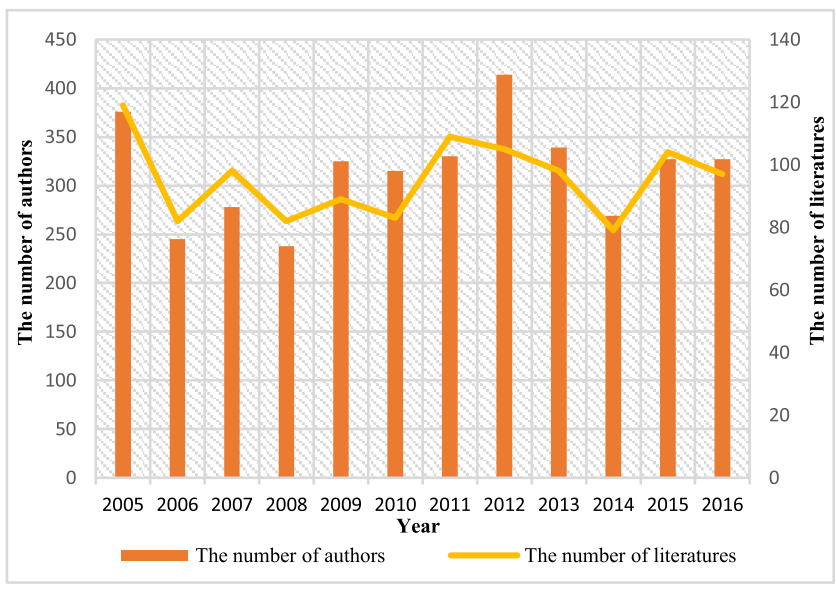

Fig. 5 Time series analysis of LOIS TC.

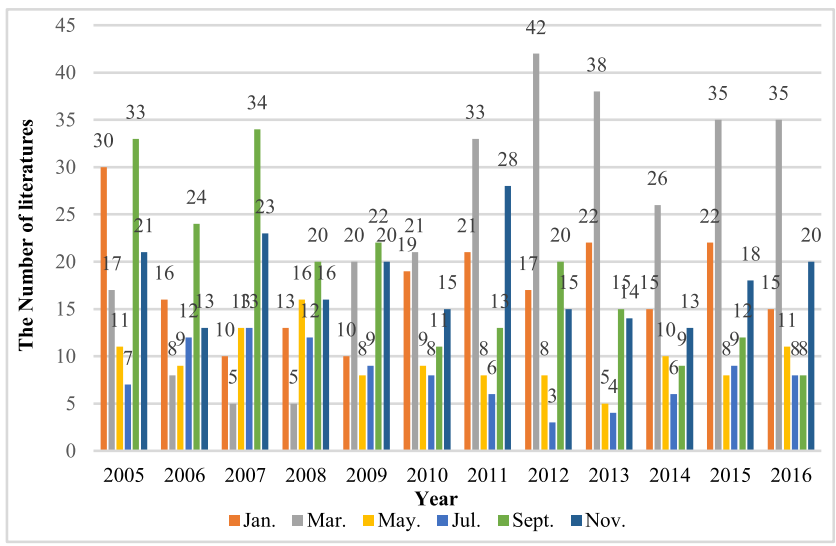

Fig. 6 Time series literature number of the LOIS TC.

Table 7 Topics and major keywords handled by LOIS TC.

\begin{tabular}{ll}
\hline Topics & Major Keywords \\
\hline Lifelog & Lifelog, Life intelligence, Log \\
\hline Office model & Office Bussiness, Cocument \\
\hline Communication & Communication, Weblog, SNS \\
\hline Data mining & Mining, Recommend, Intelligence \\
\hline System architecture & System, Service, Mashup \\
\hline Network & Network, Cloud, P2P \\
\hline Security & Security, Spam, Privacy \\
\hline Human interface & Device, Operation, Visualizatiomn \\
\hline
\end{tabular}

that the explanatin is that there are many services, such as food logging services, telephone logging services, receipt logging services, etc., which have been proposed and their experimental results are often reported. The big challenges, however, are privacy and security protection issues around the use of private personal information. Therefore the literatures covering lifelogs has been decreasing. Three figures (Fig. 5, 6 and 7) are presented as generated by an ordinary spreadsheet software from the dataset of the retrieval system.

The relation among the keywords are shown as a Key- 
word Network Map as persented in Fig. 8. In this figure, "Lifelog" is located around the center and this is related to other keywords, such as "Conversation log", "Telephony", "Multimedia", "Database", "Word spotting", and so on. Then the keyword "Office" is also linked to the keywords, such as "Business", "Office Information system", "Secretary", "Telephony", and so on.

This figure is drawn by the principle that the co- occurring keywords with "Lifelog" are linked by the edge with each other. Figure 9 shows the numbers of literatures in each LOIS TC per month. It has held in January, March, May, July, September and November. In January, the Information Management Network (IMN) TC is co-located and so as Groupware and Network Service (GN) TC and Security Psychology and Trust (SPT) TC in May. This TC is co-located with Document Communication (DC) TC in

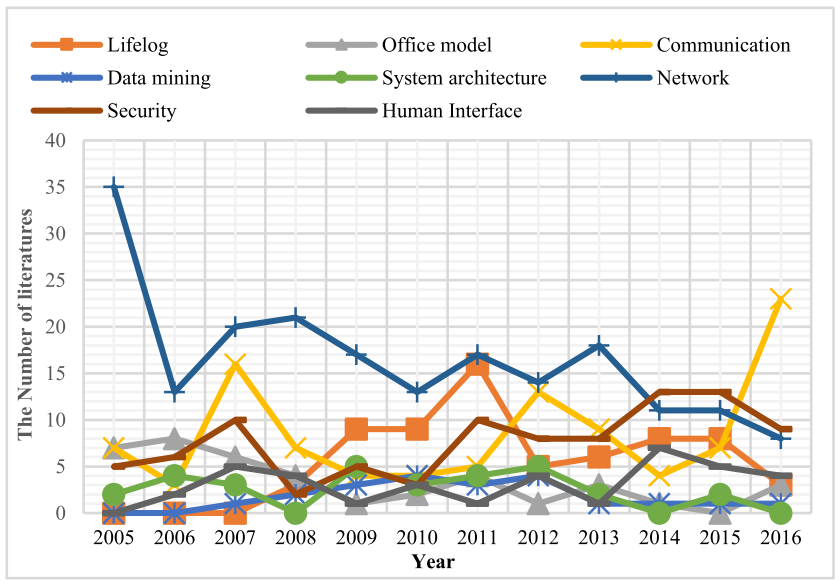

Fig. 7 Time series literature per topics.

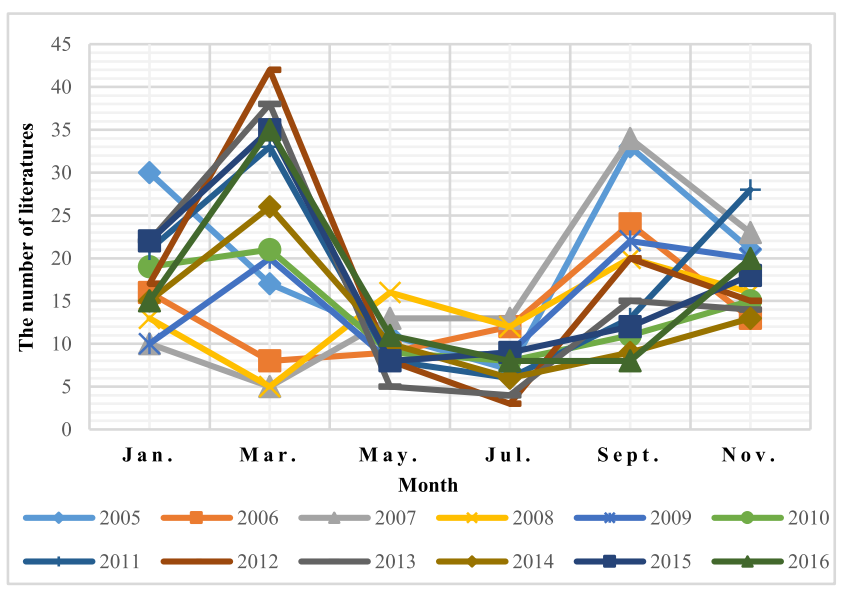

Fig.9 Article count per month

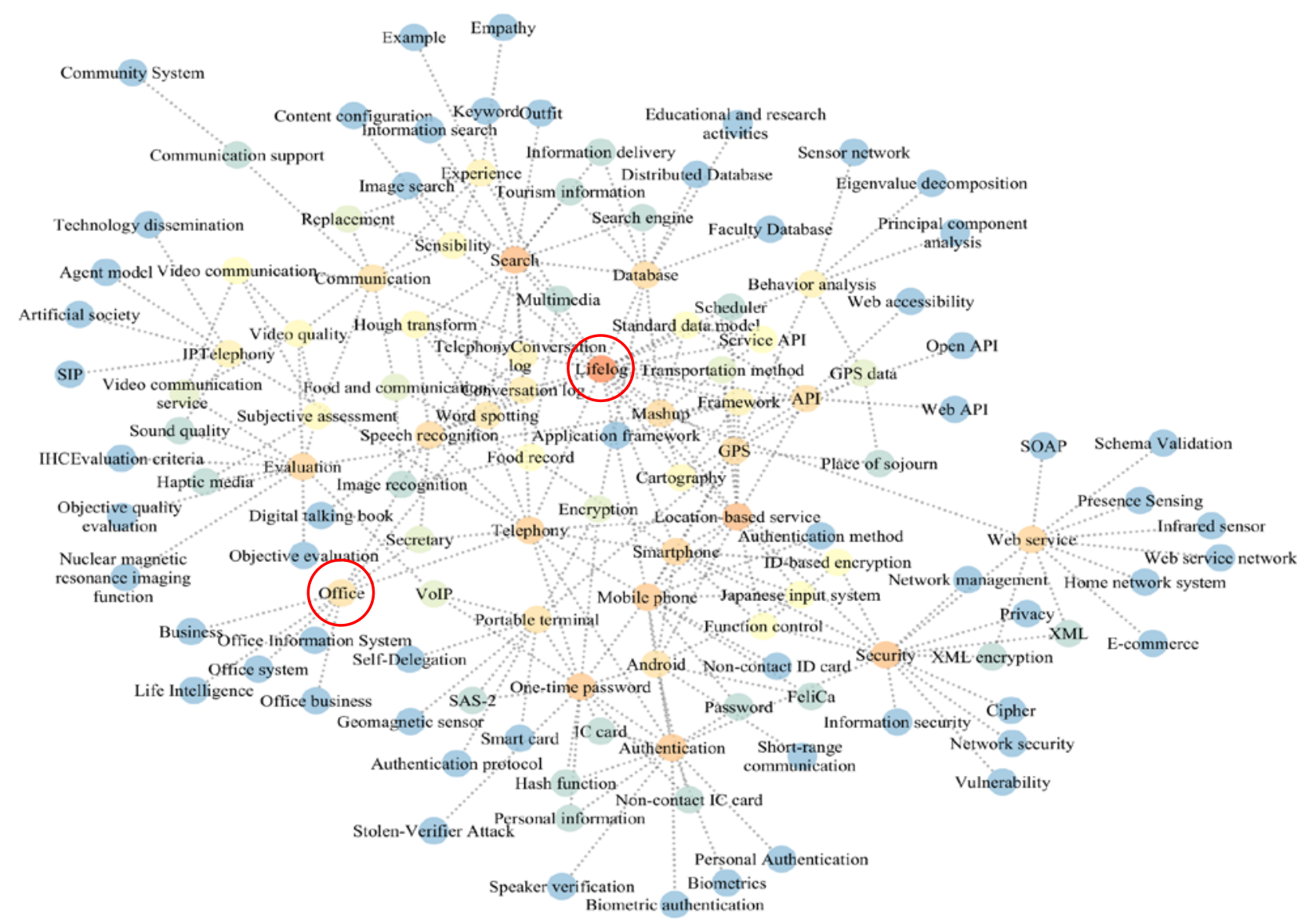

Fig. 8 Keyword network in the LOIS TC 


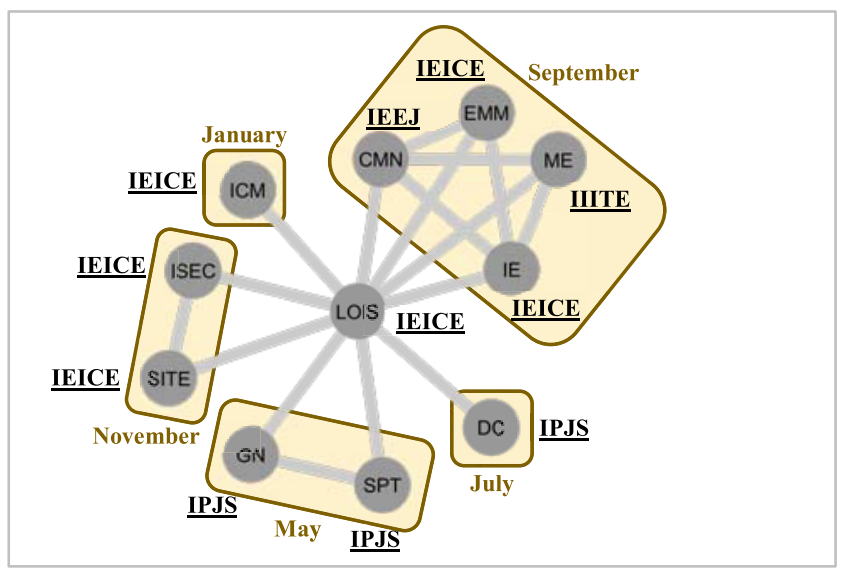

ICM: Information and Communication Management, ISEC Information SECurity, SITE: Social Implications of Technology and Information Ethics, ME: Media Engineering, CMN: Communication, EMM: Enriched Multi Media, IE: Image Engineering

DC: Document Communication, SPT: Security Psychology and Trust, GN: Groupware and Network Service

Fig. 10 Joint conference relation with other TCs

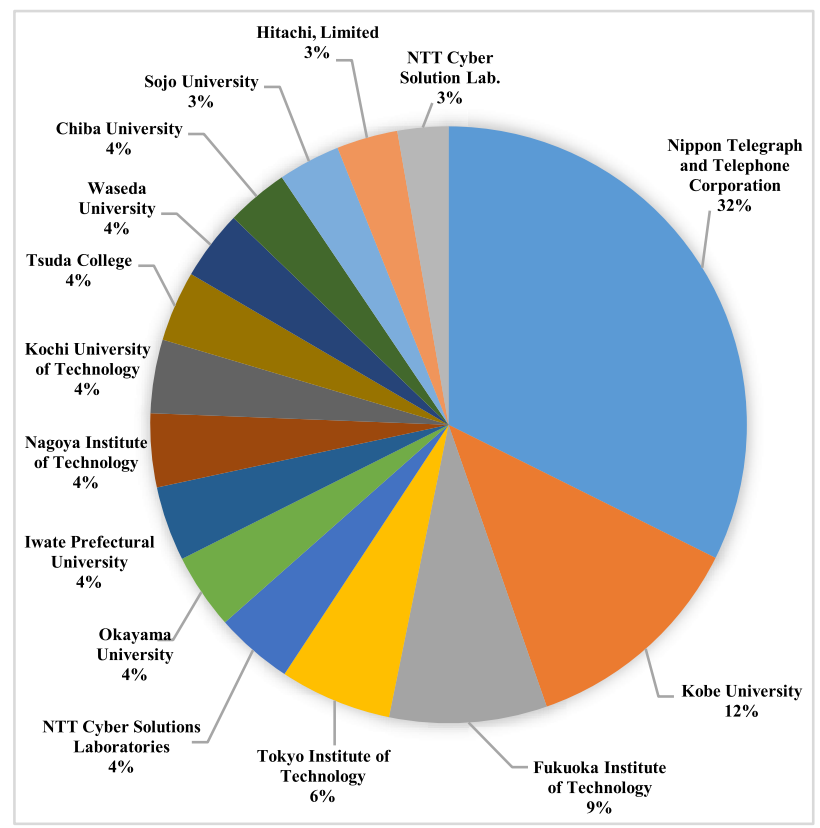

Fig. 11 Main contributors in the LOIS TC.

July. These cooperating TCs are shown in Fig. 10. Since the number of articles in July is rather small, the joint conference with Mobile Network and Application (MONA) TC in Communication Society is scheduled to start from 2017.

The main contributors of the LOIS TC are from NTT Laboratories, Kobe Univ., Kochi Univ. of Tech., Fukuoka Inst. of Tech. and so on. The top 15 contributors are shown in Fig. 11.

The keyword network graph linked with keyword "Lifelog" in 2004 is shown in Fig. 12. In this figure, there are no keywords related to "Lifelog". Then the similar keyword graph in 2008 is also shown in Fig. 13. In this figure, the keyword appears in the upper right area. The graph in 2014 is shown in Fig. 14. Comparing these graphs from

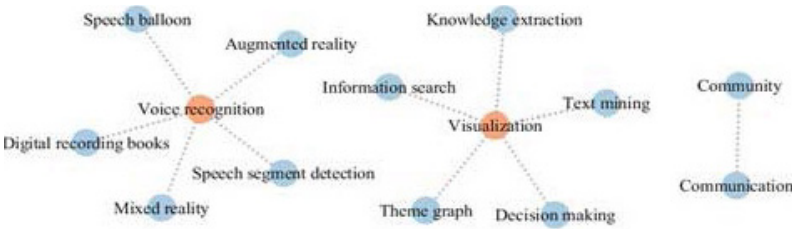

Fig. 12 Keyword network connected to Lifelog in 2004.

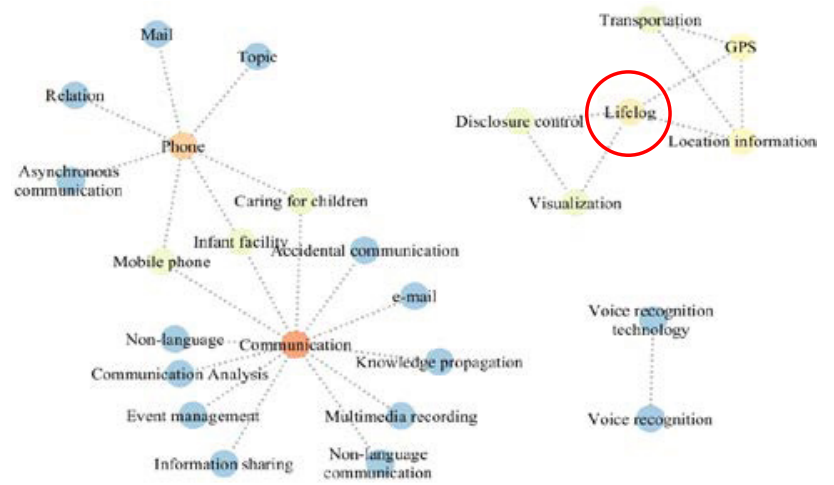

Fig. 13 Keyword network connected to Lifelog in 2008.

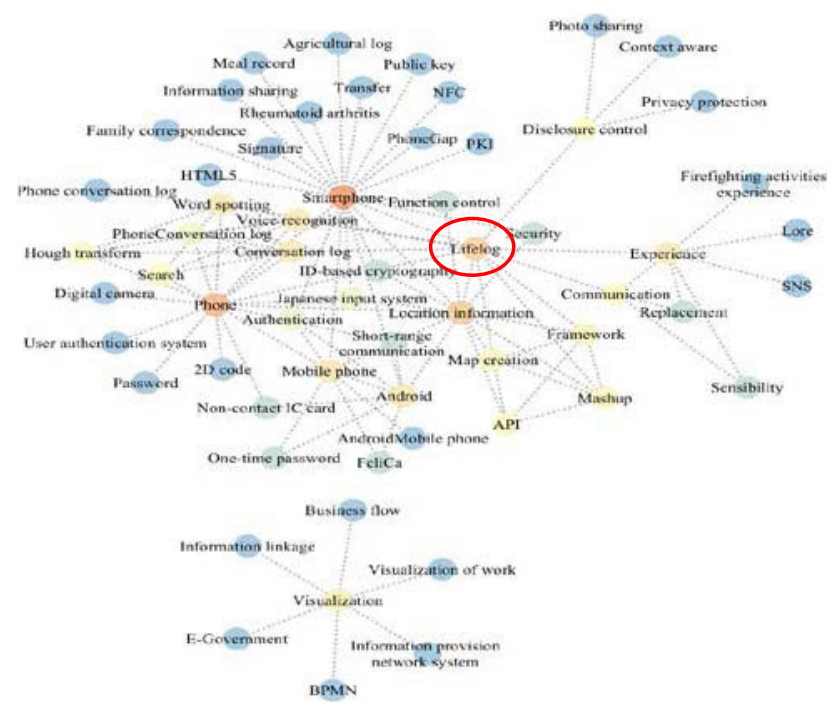

Fig. 14 Keyword network connected to Lifelog in 2012.

Fig. 12 to Fig. 14, the number of the keyword links with "Lifelog" has gradually increased and spread. This corresponds to the increase in the quantity of literature and crossreferencing with each other. It can be said that the research related to "Lifelog" has develops gradually and is in the development phase.

Figure 2 to Fig. 4 were drawn with the new literature analysis system. Other figures were drawn by using ordinary software such as, Excel and Cytoscape [13] with the datasets of I-Scover system. 


\section{Conclusions}

It has been about 30 years since the OS Technical Committee was founded. During this period, technologies for office systems have developed significantly and the name of the technical committee was changed from OS to OFS, OIS and LOIS.

- Examining the activity trends of the LOIS TC with the new literature analysis system using the I-Scover system, it is found that the TC was on a gradual decline until 2008. After the name was changed from OIS to LOIS in April 2009, it has become very active. After that, more than 70 presentations were observed over the next five years, and it can be said that the change contributed greatly to revitalization.

- Since the venue was changed from Tokyo (Machine Promotion Center) to Okinawa in March 2009, the number of presentations has increased by more than 20 and is still continuing. The conferences in March are hosted by LOIS TC alone. It seems that the March conference has become established as an event for graduation presentation for university students and researchers.

- The conference in July is held jointly with the Document Communication (DC) TC of Information Processing Society of Japan, but the number of research presentations has been small. Therefore, new strategies, such as inviting tutorials, encouraging lectures and panel discussions, will be introduced.

The LOIS TC will continue to regularly hold 6 conferences a year (in the odd months) and semi-annual FIT (Forum on Information Technology) and general conferences. It will also further invigorate research presentations by choosing the timely topics across wider society. The joint conference with Mobile Network and Applications (MONA) TC is expected to start from July 2017 as the first of its expansion strategies. Special issues of the ISS Journal (in Japanese) have been published 5 times over the past 15 years and the first one in English is being published with this volume. Finally, the authors hope further development of office related systems and technologies via LOIS TC.

\section{Acknowledgements}

The authors would like to express the thanks for contribution of all the Office related Technical Committee members and for being offering the IEICE literature datasets to the I-Scover projects [14].

\section{References}

[1] Japan Society for Information and Management, http://www.jsim.gr.jp/ en/index.html, Accessed on Oct. 25, 2016.

[2] Japan Society for Office Studies, http://www.jos-japan.jp/, Accessed on Oct. 25, 2016.

[3] IEICE, http://www.ieice.org/eng/index.html, Accessed on Oct. 25,
2016.

[4] IEICE Life Intelligence and Office Information Systems Technical Committee, http://www.ieice.org/iss/eng/TechnicalGroups/ introduction/Type1_2.html, Accessed on Oct. 25, 2016.

[5] IEICE Knowledge Discovery, http://i-scover.ieice.org/iscover/ ?lang=en, Accessed on Oct. 25, 2016.

[6] Keywords in the Technical fields table (IEICE),http://www.ieice.or.jp/ jpn/shiori/pdf/furoku_f.pdf, Accessed on Oct. 25, 2016.

[7] T. Maki and T. Wakahara, Time Series and Technology Factor Analysis using I-Scover Literature Metadata, IEICE Trans. Inf. \& Syst., vol.J99-D, no.10, pp.1002-1012, 2016 (in Japanese).

[8] T. Maki, K. Takahashi, and T. Wakahara, Study on Similarity Evaluation of Papers Data Using Wikipedia Link API for Automatic Metadata Annotation, IEICE Trans. Inf. \& Syst., vol.J97-D no.12, pp. 1705-1708, 2014 (in Japanese).

[9] CiNii Articles, http://ci.nii.ac.jp/en, Accessed on Oct. 25, 2016.

[10] F. Nishino, I-Scover -IEICE Article Search System based on Linked Data, IEICE Communication Society Magazine, no.25, pp.49-53, Summer 2013.

[11] JpGraph, http://www.asial.co.jp/jpgraph/examples.php, Accessed on Oct. 25, 2016.

[12] T. Wakahara, T. Maki, M. Okamoto, N. Yamamoto, M. Motegi, and A. Kodate, Trend Analysis of LOIS Technical Study (3), IEICE Technical Report, vol.114, no.32, LOIS2014-9, pp.97-102, 2012 (in Japanese).

[13] Cytoscape, http://js.cytoscape.org/, Accessed on Oct. 25, 2016.

[14] IEICE I-Scover Park, http://iscover-p.ieice.org/cms/i-scoverpromotion/ Accessed on Oct. 25, 2016.

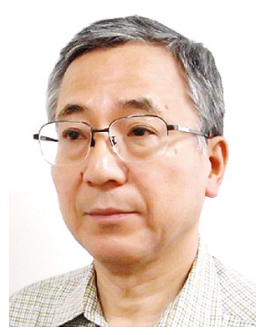

Toshihiko Wakahara received B.E., M.E. and D.E. degrees from Tokyo Institute of Technology, Tokyo, Japan in 1970, 1972 and 1998, respectively. He joined NTT Electrical Communication Laboratories in 1972 and developed PCM-FDM system and ATM application, etc. He was a Visiting Professor at the Global Information and Telecommunication Institute of Waseda University from 1999 to 2003 . He moved to Fukuoka Institute of Technology as a Professor in 2003. He received the ISS Distinguished Service Award in 2015. He is a Fellow of IEICE, a Fellow of IIEEJ and a member of IEEE, and IPSJ.

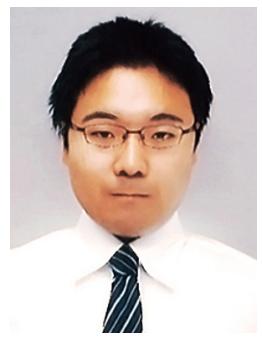

Toshitaka Maki received B.E. and M.E. degrees in Communication and Information Networking from Fukuoka Institute of Technology, Fukuoka, Japan, in 2013 and 2015. He is currently pursuing a Ph.D. degree with the Graduate School of Engineering, and is receiving the JSPS research fellowship for young scientists from April 2017 to March 2019. He received awards at the I-Scover Challenge contest in 2013, 2014 and 2017, and received Young Researcher's Award in 2014. He is a student mem-

ber of IEICE. 


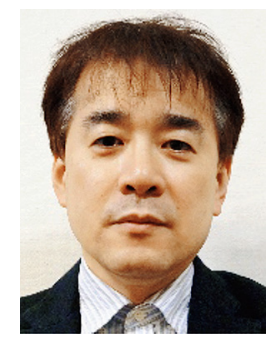

of IEICE and IPSJ.
Noriyasu Yamamoto received B.E. degree from the University of Nagasaki, Japan, in 1990. He received M.E. and Ph.D. degrees from the University of Kyushu, Japan, in 1992 and 1998, respectively. He is currently a Professor in the Fukuoka Institute of Technology. He conducts active research in various information technology related areas including computer vision, distributed (massively parallel) image processing, security on the network and logging system for human (Life-Log). He is a member

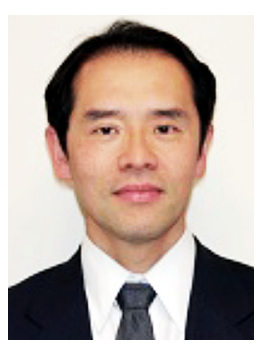

Akihisa Kodate received his Bachelor of Engineering in 1992, Master of Engineering in 1994 and Doctor of Engineering in 2000, all from Waseda University, Tokyo, Japan. He was a researcher at University of Hannover, Germany and a visiting Associate Professor at the Global Information and Telecommunication Institute of Waseda University. Since 2012, he has been a Professor and the Director of the Center for Women in Research of Tsuda University. He has been engaged in the research of multimedia signal processing and its applications and information systems, such as video content analysis and personal life-logging services. He is a senior member of IEICE and a member of IEEE and IPSJ.

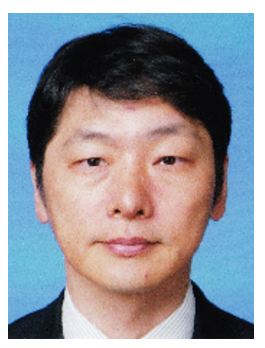

Manabu Okamoto received M.Design degree from Kyushu Institute of Design, Japan, in 1991 and Doctor of Design from Kyushu University, Japan, in 2007. In 1991, he joined NTT Electrical Communication Laboratories. Since then, he has been researching the acoustic design of various kinds of teleconferencing systems and the system design of ICT services. He is currently engaged in speech recognition research. He is a senior member of IEICE and a member of ASJ and IEEE.

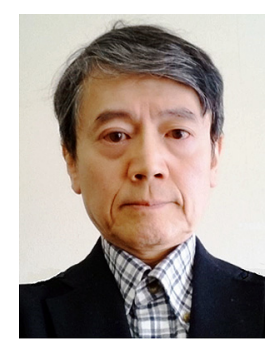

Hiroyuki Nishi received B.E. and M.E. degrees in electronics from Kyushu University in 1977 and 1979, respectively. He worked at NTT's laboratories from 1979 to 2002 and received a Ph.D. from Tsukuba University in 2003. He is a professor of Sojo University and Dean of Faculty of Computer and Information Sciences. He is currently interested in observation systems for elderly people using acoustic recognition and machine learning. He is a senior member of IEICE and the chair of the LOIS TC. 